\title{
MTA HP Repair stimulates in vitro an homogeneous calcium phosphate phase coating deposition
}

\author{
María del Carmen Jiménez-Sánchez ${ }^{1,2}$, Juan J. Segura-Egea ${ }^{1}$, Aránzazu Díaz-Cuenca ${ }^{2,3}$ \\ ${ }^{1}$ Department of Stomatology, Faculty of Dentistry, University of Sevilla, Sevilla, Spain \\ ${ }^{2}$ Materials Science Institute of Sevilla (ICMS), Joint CSIC-University of Sevilla Center, Sevilla, Spain \\ ${ }^{3}$ Networking Research Center on Bioengineering, Biomaterials and Nanomedicine (CIBER-BBN), Spain
}

Correspondence:

Department of Stomatology

Faculty of Dentistry

University of Sevilla

Sevilla, Spain

aranzazu@icmse.csic.es

Received: 20/02/2019

Accepted: 13/03/2019

\begin{abstract}
Jiménez-Sánchez MC, Segura-Egea JJ, Díaz-Cuenca A. MTA HP Repair stimulates in vitro an homogeneous calcium phosphate phase coating deposition. J Clin Exp Dent. 2019;11(4):e322-6.

http://www.medicinaoral.com/odo/volumenes/v11i4/jcedv11i4p322.pdf
\end{abstract}

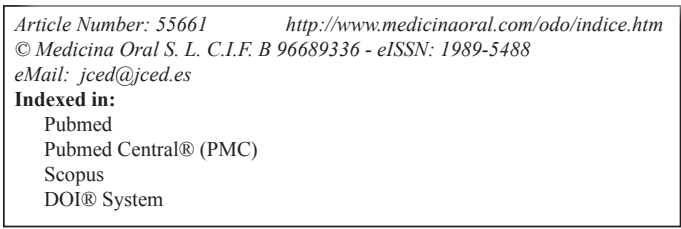

\begin{abstract}
Background: To study the mineralization capacity in vitro of the bioceramic endodontic material MTA HP Repair. Material and Methods: Bioactivity evaluation in vitro was carried out, by soaking processed cement disk in simulated body fluid (SBF) during $168 \mathrm{~h}$. The cement surface was studied by Fourier transform infrared spectroscopy (FTIR), field emission gun scanning electron microscopy (FEG-SEM) and energy dispersive X-ray analysis (EDX). Release to the SBF media of ionic degradation products was monitored using inductively coupled plasma atomic emission spectroscopy (ICP-AES).

Results: FT-IR showed increasing formation of phosphate phase bands at 1097, 960, 607 and $570 \mathrm{~cm}^{-1}$ with prolonged SBF soaking. FEG-SEM analysis reveals that HP produces a effectively surface covering consisting in homogeneous spherical phosphate phase aggregates with an average diameter of 0.5-1.0 $\mu \mathrm{m}$. EDX analysis comparing un-treated (hydrated), $24 \mathrm{~h}$ and $72 \mathrm{~h} \mathrm{SBF}$ treated surfaces of MTA HP Repair revealed phosphate deposition after 24 $\mathrm{h}$, with high phosphorous/silicon element ratio signal measured after $24 \mathrm{~h}$, indicating a very high phosphate phase deposition for this material.

Conclusions: The study shows that MTA HP Repair produces a quick and effective bioactive response in vitro in terms of crystalline calcium phosphate surface coating formation. The high bioactive response of MTA HP Repair makes it an interesting candidate for endodontic use as repair cement.
\end{abstract}

Key words: Bioactive endodontic cements, bioactive response, MTA HP Repair.

\section{Introduction}

Bioceramic endodontic cements (BECs), such as Mineral Trioxide Aggregate (MTA) and related materials, stimulate the natural remineralization process at the material-tooth interface (1). Therefore, they are considered bioactive endodontic cements (2), being applied as active therapeutic agent to stimulate regeneration (3-6).
Calcium silicates $\left(\mathrm{Ca}_{3} \mathrm{SiO}_{5}\right.$ and $\left.\mathrm{Ca}_{2} \mathrm{SiO}_{4}\right)$ are the base compounds of BECs, together with radiopacifying additives such as bismuth, zirconia, tantalum, or tungsten oxides $(2,7)$. Calcium silicate based cements, particularly those containing bismuth oxide as radiopacifier (8), present some disadvantages such as tooth discoloration, long setting time or difficult handling (9). Consequently, 
new BECs have been prepared replacing bismuth oxide with alternative radiopacifier materials $(9,10)$.

MTA Repair HP (Angelus, Londrina, Brasil) is a new BEC in which, bismuth oxide has been replaced by calcium tungstate $\left(\mathrm{CaWO}_{4}\right)$ as radiopacifier and this modification of cement composition will alter the physico-chemical characteristics and the biomechanical properties of the bioceramic material $(2,11,12)$, and could also modify the biological functional properties $(2,13,14)$. The aim of this study is to assess the mineralization capacity and bioactive response in vitro of the bioceramic endodontic cement MTA HP Repair (HP).

\section{Material and Methods}

MTA HP Repair (Angelus, Londrina, Brasil) was used in this study. The composition of the bioceramic as the manufacturer specifications is: tricalcium silicate $\left(\mathrm{Ca}_{3} \mathrm{SiO}_{5}\right)$, dicalcium silicate $\left(\mathrm{Ca}_{2} \mathrm{SiO}_{4}\right)$, calcium tungstate $\left(\mathrm{CaWO}_{4}\right)$ as radiopacifier, tricalcium aluminate $\left(3 \mathrm{CaO} \cdot \mathrm{Al}_{2} \mathrm{O}_{3}\right)$, and calcium oxide $(\mathrm{CaO})$.

The in vitro bioactivity evaluation was assessed, by soaking the cement disks in $13 \mathrm{~mL}$ of simulated body fluid (SBF) (15) during 4, 24, 72 and $168 \mathrm{~h}$ at $36.5{ }^{\circ} \mathrm{C}$ and 60 r.p.m. shaking using polytetrafluoroethylene beakers. Previously to the bioactivity assay, the samples were sterilized under UV light for $10 \mathrm{~min}$ period on each side. SBF solution was filtered using $0.2 \mathrm{~mm}$ bacteriostatic filter (Biofil).

Fourier transform infrared (FT-IR) spectra of as-processed set material and the SBF treated samples were collected in transmission configuration in the 1300-400 $\mathrm{cm}^{-1}$ range using $4 \mathrm{~cm}^{-1}$ intervals in a Nicolet IS50 FTIR (Thermo Scientific, Madison WI, USA). The microstructures were studied by field emission gun scanning electron microscopy (FEG-SEM) using a HITACHI S-4800 (Tokyo, Japan). Images were recorded at an accelerating voltage of $2 \mathrm{kV}$. Energy dispersive X-ray (EDX) analysis was carried out at $10 \mathrm{kV}$ with an EDX Bruker XFlash 4010 detector. Concentrations of $\mathrm{Si}, \mathrm{Ca}$, $\mathrm{P}, \mathrm{W}$ and $\mathrm{Al}$ ions in the soaking media were monitored after 72 and $168 \mathrm{~h}$ by inductively coupled plasma atomic emission spectroscopy (ICP-AES) using the spectrometer Horiba Jobin Yvon (Ultima 2, Paris, France). Control solutions consisting of pure SBF was simultaneously prepared and stored under the same conditions.

\section{Results}

The FT-IR absorbance spectra of MTA HP Repair after the analysed SBF treatment times, in comparison with the spectra of the as-set (SBF un-treated) sample, are shown in Figure 1. An important intensity increase with treatment time, of calcium silicate hydrate C-S-H broad band within the $1000-1100 \mathrm{~cm}^{-1}$ range is observed. Likewise, increasing formation of phosphate phase bands at $1097,960,607$ and $570 \mathrm{~cm}^{-1}(16)$, are clearly obser-

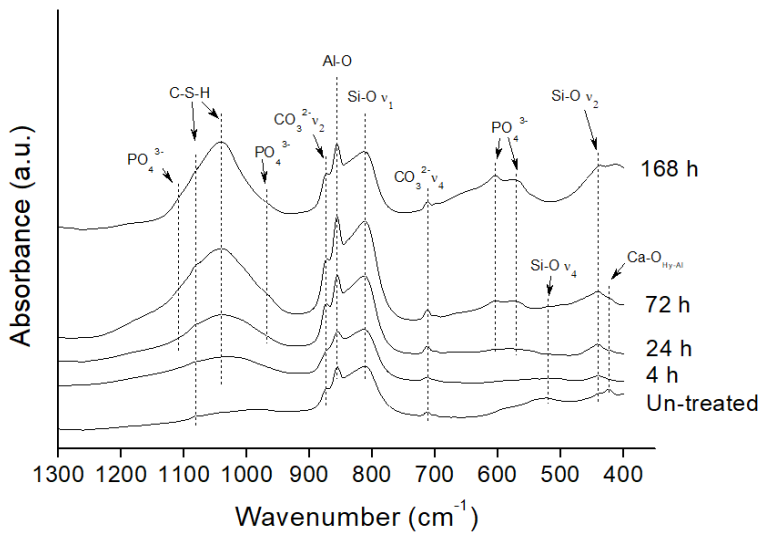

Fig. 1: Fourier transform infrared (FT-IR) spectra of MTA HP Repair after SBF treatment of the different analysed times plotted together with the spectra of the SBF un-treated samples. (S-C-H = calcium silicate hydrate).

ved with prolonged SBF soaking. Calcium hydroxyapatite growing on the MTA HP Repair surface after $72 \mathrm{~h}$ treatment can be inferred from the two bands at 607 and $570 \mathrm{~cm}^{-1}$ characteristics of phosphate in a crystalline environment (17). Incipient signals at 607 and $570 \mathrm{~cm}^{-1}$ are observed at only $24 \mathrm{~h} \mathrm{SBF}$ treatment.

Back-scatter FEG-SEM micrographs of the un-treated MTA HP Repair set material surface (a, b), as well as

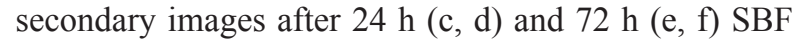
treatment, at two different magnifications are presented in Figure 2. New homogeneous spherical aggregate formations covering the surface of the SBF treated samples are observed after $24 \mathrm{~h}$ soaking time, showing average diameter spheres in the 0.5-1.0 $\mu \mathrm{m}$ range. After $72 \mathrm{~h}$ SBF treatment, a visible growing in size of the spherical features is observed. Besides, prismatic features characteristic of calcium apatite-like structure with hexagonal symmetry, growing out of the spherical formations are clearly visible in Figure 3. Calcium phosphate deposition is confirmed by EDX analysis. Un-treated, $24 \mathrm{~h}$ and $72 \mathrm{~h}$ SBF treated surfaces of MTA HP Repair are displayed in Figure 4. The analysis reveals the detection of a high phosphorous signal after only $24 \mathrm{~h}$, indicating a very high phosphate phase deposition for this material. $\mathrm{Si}, \mathrm{Ca}, \mathrm{P}, \mathrm{W}$ and $\mathrm{Al}$ ionic product in solution after 72 and $168 \mathrm{~h}$ SBF soaking treatment are presented in Table 1. Si and $\mathrm{Ca}$, major BEC material components, elution indicates material dissolution. $\mathrm{W}$ and $\mathrm{Al}$ ions were also detected in solution being $\mathrm{Al}$ particularly high, showing up to $0.4 \mathrm{mg} \mathrm{L}^{-1}$ concentration after $168 \mathrm{~h}$.

\section{Discussion}

Calcium phosphate mineralization capacity of MTA HP Repair, a bioceramic cement with calcium tungstate as radiopacifier used in endodontic therapy, has been studied. Bioactivity assay in vitro indicates that MTA HP Repair forms a structured crystallized calcium phospha- 

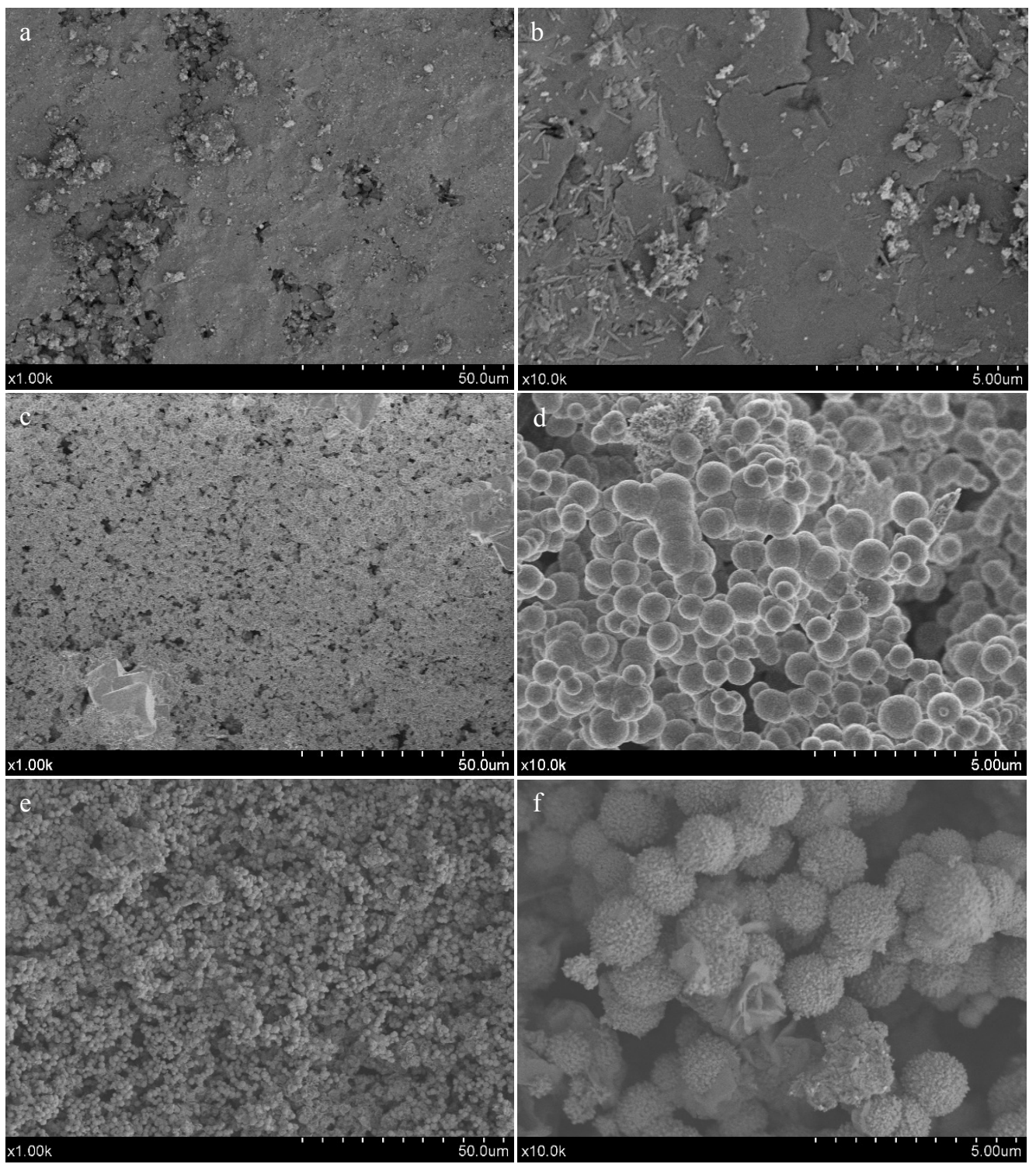

Fig. 2: Field emission gun scanning electron microscopy (FEG-SEM) of MTA HP Repair. Back- scatter electron micrographs of un-treated surfaces (a, b); and secondary electron micrographs after $24 \mathrm{~h}(\mathrm{c}-\mathrm{d})$ and $72 \mathrm{~h}$ (e-f) SBF treatment. Scale bars: (left (50 um); right (5 um)).

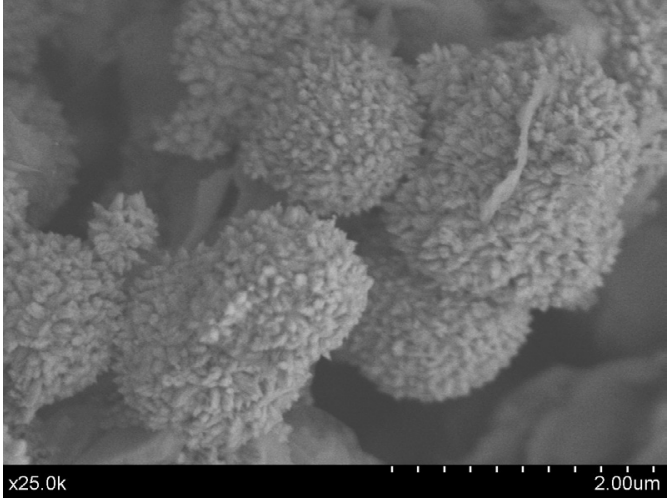

Fig. 3: Field emission gun scanning electron microscopy (FEG-SEM) of MTA HP Repair: secondary electron micrograph after $72 \mathrm{~h} \mathrm{SBF}$ treatment. Scale bar: $(2 \mu \mathrm{m})$.

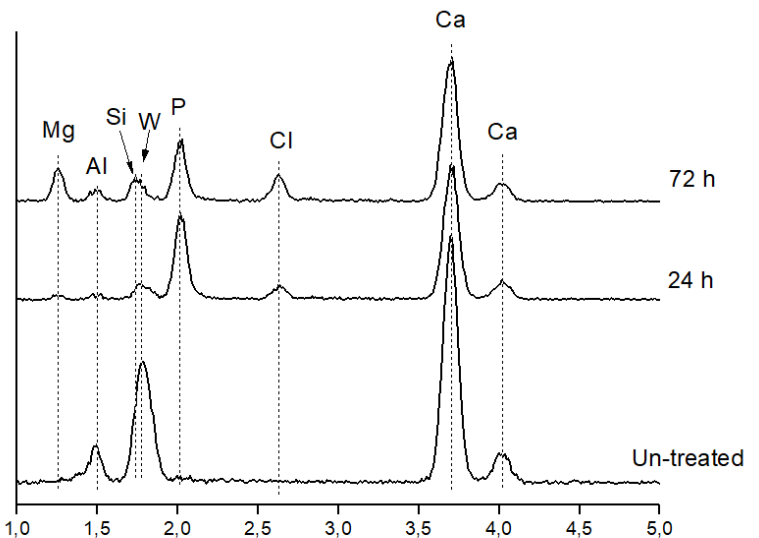

Fig. 4: Energy dispersive X-ray (EDX) analyses of un-treated and after $24 \mathrm{~h}$ and $72 \mathrm{~h} \mathrm{SBF}$ treatment of MTA HP Repair. 
te coating layer after $72 \mathrm{~h}$ treatment. FEG-SEM observations of MTA HP Repair surface after $24 \mathrm{~h}$ only SBF treatment, shows a phosphate phase coating formed of homogeneous spheres with an average diameter in the $0.5-1.0 \mu \mathrm{m}$ range. This high bioactive response might be associated to the high calcium aluminate content of this formation of a mineralised biomimetic cement-tissue interphase. A recent investigation carried out by Qiu et al. (21) using MTA extract has shown that concentrations of $\mathrm{Ca}$ ions of $88.9 \mathrm{mg} \mathrm{L}-1$ and $\mathrm{Si}$ ions of $0.22 \mathrm{mg} \mathrm{L}^{-1}$ in the culture medium promote the repair of injured pulp, potentially by accelerating proliferation and reducing the

Table 1: $\mathrm{Si}, \mathrm{Ca}, \mathrm{P}, \mathrm{W}$ and $\mathrm{Al}$ ionic product degradation concentration in the SBF soaking media of MTA HP Repair material monitored by inductively coupled plasma atomic emission spectroscopy (ICP-AES).

\begin{tabular}{|l|c|c|c|}
\hline Element $\left(\mathrm{mg} \mathrm{L}^{-1}\right)$ & $\begin{array}{c}\text { SBF } \\
\text { as-prepared solution }\end{array}$ & \multicolumn{2}{|c|}{$\begin{array}{c}\text { SBF } \\
\text { soaking media }\end{array}$} \\
\hline & & $72 \mathrm{~h}$ & $168 \mathrm{~h}$ \\
\hline Silicon & --- & $12.800 \pm 0.424$ & $12.200 \pm 0.140$ \\
\hline Calcium & $96.900 \pm 1.802$ & $650.000 \pm 31.005$ & $824.000 \pm 14.255$ \\
\hline Phosphorus & $31.100 \pm 0.351$ & $\leq 0.004$ & $\leq 0.004$ \\
\hline Tungsten & --- & $0.106 \pm 0.002$ & $0.070 \pm 0.005$ \\
\hline Aluminium & --- & $0.016 \pm 0.001$ & $0.401+0.004$ \\
\hline
\end{tabular}

material (18), and to the great surface degradation, as measured by the $\mathrm{Si}$ and $\mathrm{Ca}$ ion product release, detected by ICP. The nucleation of the calcium phosphate phase would be favoured by the change in the chemical composition and in the $\mathrm{pH}$ of the solution resulting from the accumulation of dissolution products from the MTA HP Repair, with the appearance of new surface sites (19). Particularly, the repolymerization of a porous silica-rich layer through silanol groups condensation from the soluble silica in the form of $\mathrm{Si}(\mathrm{OH})_{4}$, followed by the migration of $\mathrm{Ca}^{2+}$ and $\mathrm{PO}_{4}^{3-}$ groups to the surface forms a film rich in amorphous $\mathrm{CaO}-\mathrm{P}_{2} \mathrm{O}_{5}$.

The clinical manifestation of bioactivity with the use of BECs has been attributed to phosphate phase's mineralization induction capacity (16) and compared to that of calcium hydroxide postulating that the mechanisms of action were similar (20). When MTA HP Repair is exposed to a phosphate-containing media such as SBF, a series of reactions take place on the surface between calcium from the cement and phosphate from the solution consisting of the absorption of $\mathrm{Ca}$ and $\mathrm{P}$ ions on the silica-rich (C-S-H) surface and the precipitation of $\mathrm{HPO}_{4}{ }_{4}^{2-}$ containing phase which matures into a crystalline hydroxycarbonate apatite phase at increasing treatment times. Micrograph in Figure 3 displays, resolved elongated nano-metrical grains with crystalline morphology growing out of spherical formations, which have been confirmed as calcium phosphate composition by FT-IR and EDX. We argue that, the new formed calcium phosphate layer could filled the superficial crack and voids providing a stable sealing at cement surface. Also, that phosphate ions able to promote apatite deposition, from biological fluids and blood present at the external surface during surgical procedures, could well enhance the time required for hDPCs to enter into the odontoblastic differentiation stage in the clinical setting.

The results of the present study indicates that MTA HP Repair produces a quick and effective bioactive response in vitro in terms of HA surface coating formation. The high bioactivity response for HP is in good accordance with its high calcium aluminate content. Recently, a study carried out on human dental pulp stem cells has demonstrated the high biocompatibility and cytocompatibility of MTA Repair HP (7).

\section{Conclusions}

Bioactivity essay in vitro indicates that MTA HP Repair produces a quick and effective bioactive response in $v i$ tro in terms of homogeneous calcium phosphate surface coating formation. MTA HP Repair stimulates the formation of a nanostructured calcium phosphate coating layer after $72 \mathrm{~h}$ treatment. The high bioactive response of MTA HP Repair makes it ideal for endodontic use as repair cement.

\section{References}

1. Torabinejad M, Chivian N Clinical applications of mineral trioxide aggregate. J Endod. 1999; 25:197-205.

2. Parirokh M, Torabinejad M, Dummer PMH. Mineral trioxide aggregate and other bioactive endodontic cements: an updated overview - part I: vital pulp therapy. Int Endod J. 2018; 51:177-205.

3. Rodrigues EM, Gomes-Cornélio AL, Soares-Costa A, Salles LP, Velayutham M, Rossa-Junior C, Guerreiro-Tanomaru JM, Tanomaru-Filho M. An assesment of the overexpression of BMP-2 in transfected human oesteoblast cells stimulated by mineral trioxide aggregate and Biodentine. Int Endod J. 2017; 50: 9-18.

4. Silva GF, Guerreiro-Tanomaru JM, da Fonseca TS, Bernardi MIB, Sasso-Cerri E, Tanomaru-Filho M, Cerri PS. Zirconium oxide and niobium oxide used as radiopacifiers in a calcium silicate-based material stimulate fibroblast proliferation and collagen formation. Int Endod J. 2017; 50:e95-e108. 
5. Marí-Beffa M, Segura-Egea JJ, Díaz-Cuenca A. Regenerative Endodontic Procedures: A Perspective from Stem Cell Niche Biology. J Endod. 2017; 43:52-62.

6. Chang F, Kim JM, Choi Y, Park K. MTA promotes chemotaxis and chemokinesis of immune cells through distinct calcium-sensing receptor signaling pathways. Biomaterials. 2018; 150:14-24.

7. Tomás-Catalá CL, Collado-Gozález M, García-Bernal, D, O-ate-Sánchez, Forner L, Llena C, Lozano A, Castelo-Baz P, Moraleda JM, Rodríguez-Lozano FJ. Comparative analysis of the biological effects of the endodontic bioactive cements MTA-Angelus, MTA Repair HP and NeoMTA Plus on human dental pulp stem cells. Int Endod J. 2017; 50:63-72.

8. Gandolfi MG, Siboni F, Primus CM, Prati C. Ion release, porosity, solubility, and bioactivity of MTA Plus tricalcium silicate. J Endod. 2014; 40:1632-7.

9. Camilleri J. Characterization of hydration products of mineral trioxide aggregate. Int Endod J. 2008; 41:408-17.

10. Vallés M, Mercadé M, Duran-Sindreu F, Bourdelande JL, Roig M. Influence of light and oxygen on the color stability of five calcium silcate-based materials. J Endod. 2013; 39:525-528.

11. Kogan P, He J, Glickman GN, Watanabe I. The effects of various additives on setting properties of MTA. J Endod. 2006; 32:569-572.

12. Huang TH, Shie MY, Kao CT, Ding SJ. The effect of setting accelerator on properties of mineral trioxide aggregate. J Endod. 2008; 34:590-593.

13. Ber BS, Hatton JF. Chemical modification of ProRoot MTA to improve handling characteristics and decrease setting time. J Endod. 2007; 33:1231-1234.

14. Camilleri J, Sorrentino F, Damidot D. Investigation of the hydration and bioactivity of radiopacified tricalcium silicate cement, Biodentine and MTA Angelus. Dent Mat. 2013; 29:580-593.

15. Kokubo T, Takadama H. How useful is SBF in predicting in vivo bone bioactivity?. Biomaterials. 2006; 27:2907-2915.

16. Tay FR, Pashley DH, Rueggeberg FA, Loushine RJ, Weller RN. Calcium phosphate phase transformation produced by the interaction of the portland cement component of white mineral trioxide aggregate with a phosphate-containing fluid. J Endod. 2007; 33:1347-1351

17. Salinas AJ, Vallet-Regí M. Bioactive ceramics: from bone grafts to tissue engineering. RSC Adv. 2013;3:11116-11131.

18. Taddei P, Modena E, Tinti A, Siboni F, Patri C, Gandolfi MG. Effect of the fluoride content on the bioactivity of calcium silicate-based endodontic cements. Ceram Int. 2014; 40:4095-107.

19. Hench LL. Bioceramics - from concept to clinic. J Am Ceram Soc. 1991; 74:1487-1510.

20. Camilleri J, Pitt Ford TR. Mineral trioxide aggregate: a review of the constituents and biological poperties of the material. Int Endod J. 2006; 39:747-754.

21. Qiu W, Sun B, He F, Zhang Y. MTA-induced Notch activation enhances the proliferation of human dental pulp cells by inhibiting autophagic flux. Int Endod J. 2017; 50:52-62.

Acknowledgements

MCJS acknowledges the financial support provided by the University of Sevilla Fellowship PhD Program.

\section{Conflict of Interest}

The authors have declared that no conflict of interest exist. 